\title{
3D MODELS, QR-CODES AND PARCEL-CODES AS AN INNOVATIVE METHOD OF VOLUMETRIC ASSESSMENT AND CERTIFICATION OF OIL-CONTAMINATED SITES
}

\author{
Elvina Mukhametshina ${ }^{1, *}$, and Ibragim Aitov ${ }^{2}$ \\ ${ }^{1}$ Industrial University of Tyumen, 628616 Nizhnevartovsk, Russian Federation \\ ${ }^{2}$ Industrial University of Tyumen, 628616 Nizhnevartovsk, Russian Federation
}

\begin{abstract}
The article describes an innovative method of volumetric assessment and certification of oilcontaminated land plots, which allows us to give an accurate assessment of the volume content of some limiting factors (in this work we considered such factors as oil pollution, chloride concentration and $\mathrm{pH}$ ). This technique involves building 3D models, tabular systematization of concentrations and volumes of oil pollution, and improving the certification of the above-mentioned areas using special QR codes and parcel codes created by us. The method described by us makes it easier and at the same time increases the objectivity of certification of oil-contaminated land plots, reflects the qualitative and quantitative volumetime parameters of plots, increases the convenience, efficiency and reliability of accounting, data transmission and storage. To speed up the processing of information, we suggest using new forms of its representation (parcel codes). Parcel codes are an intermediate link for creating QR codes.
\end{abstract}

\section{Introduction}

During the study, we analyzed several sources indexed in the Scopus and Web of Science databases. After reading the sources, we came to the conclusion that this problem, addressed in our work, namely the threedimensional representation of oil-contaminated sites and their certification, is not considered in any source. This means that our work is relevant. This work is a continuation of the study "3D-MODELS AS A METHOD FOR REFLECTING VOLUME AND SPATIAL PARAMETERS OF OIL-CONTAMINED SITES" [1].

In the works that we considered, various land reclamation methods and types were proposed to ensure environmental safety in the construction and reconstruction of oil and gas fields, in the development of mineral deposits, in the extraction of minerals, etc. [26]. However, the articles we have analyzed do not propose a methodology for creating three-dimensional models that allow us to show the color and volume of the content of oil products, chlorides, and the concentration of acidity in soils for the most effective reclamation.

In the analyzed works, the authors proposed various chemical reagents for reclamation works, such as, for example, industrial humates for the reclamation of oilcontaminated peat soils [7-8]. Methods for cleaning and reclamation of soils contaminated with oil and oil products are also proposed [9]. A number of articles describe the features of biological land reclamation of oil-contaminated and technologically saline soils [10], many assess the ecological state of soils [11], analyze the basics of environmental safety and land reclamation, as well as environmental protection [12-15].

\section{Methods}

\subsection{Take photos of the surveyed area and create a map of the required scale}

The primary task that we faced at the beginning of the study was the topographic survey of the land under study and the creation of a map of the required scale. Map diagrams were created using the Geo-Information System (Geo-Information System), one of the most famous software products for cartography and geographical analysis. The scale of 1:100000 was used when creating map diagrams. Then the sections were divided into parts: allotments and parcels. Forming a hierarchical system of 3 levels for each site. 1 the smallest level - the parcel, as one of the four layers within the boundaries of the selection; 2 level-the selection of the site with a set of four parcels; 3 level the entire site in the aggregate of allotments and parcels (fig. 1).

\subsection{Soil sampling at sites. To carry out quantitative chemical analysis}

We carried out sampling from parcels (depths) from 0-10 $\mathrm{cm}, 20-30 \mathrm{~cm}, 40-60 \mathrm{~cm}, 90-110 \mathrm{~cm}$ (the last parcel is inaccessible). The results of quantitative chemical

${ }^{*}$ Corresponding author: muhametshina.elwina2015@yandex.ru 


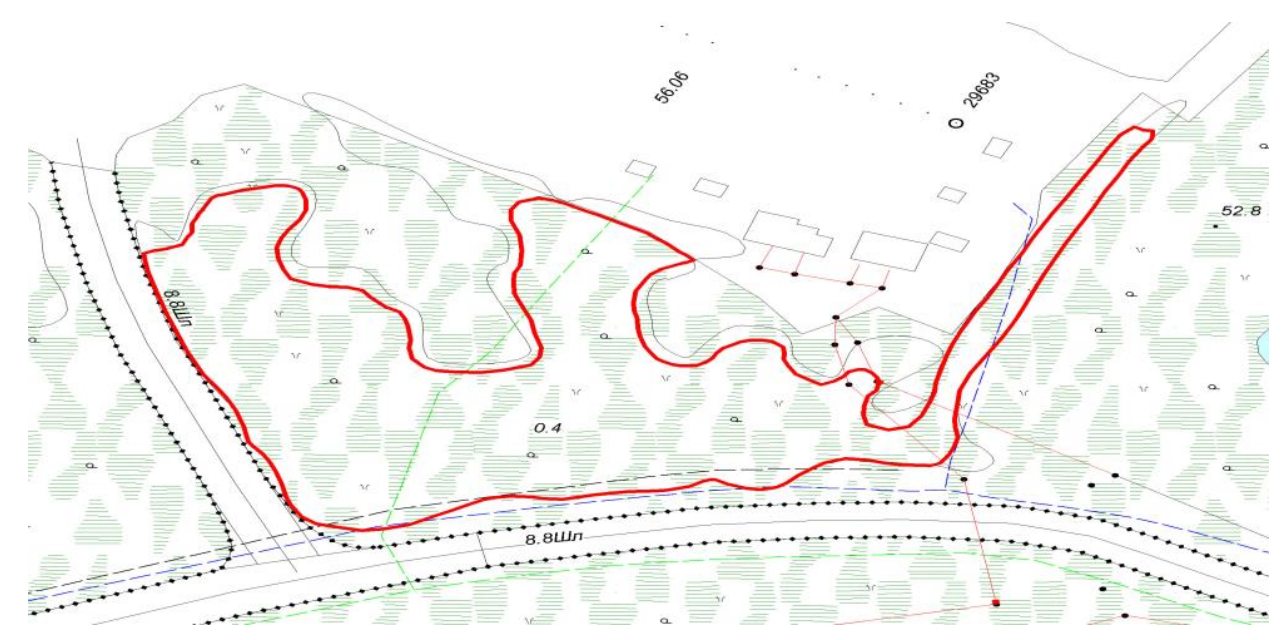

Fig. 1. Map of the area under study.

analysis are shown in figure 2. A standard chemical analysis of the soil evaluates the following parameters: $\mathrm{pH}$, petroleum products, and chloride concentration. Further, the results of the soil study are compared with the maximum permissible concentrations (MPC) in this region. Based on this comparison, the total soil pollution coefficient is calculated.

\subsection{Registration of the results of quantitative chemical analysis in tabular form}

Scaling and coloring of $\mathrm{pH}$ values and the content of oil pollution, chlorides. Calculation of the volumes of deposits, deep seams and pollution.

\begin{tabular}{|c|c|c|c|c|c|}
\hline \multirow{4}{*}{$\begin{array}{c}\text { The } \\
\text { number } \\
\text { of } \\
\text { sampling } \\
\text { site }\end{array}$} & \multirow{4}{*}{$\begin{array}{l}\text { Sampling } \\
\text { depth, } \\
\text { cm }\end{array}$} & \multicolumn{4}{|c|}{ The determined indicator } \\
\hline & & \multicolumn{2}{|c|}{ The oil products } & The chlorides & The acidity \\
\hline & & \multicolumn{2}{|c|}{ Contents } & \multirow{2}{*}{ Contents } & \multirow{2}{*}{ Contents } \\
\hline & & $\mathrm{mg} / \mathrm{kg}$ & $\%$ & & \\
\hline \multirow{4}{*}{83} & $0-10$ & 060661 & 6.1 & $3378(0.34)$ & 5.5 \\
\hline & $20-30$ & 118130 & 11.8 & $2549(0.25)$ & 5.6 \\
\hline & $40-60$ & 050700 & 5.1 & $7345(0.73)$ & 4.8 \\
\hline & $90-110$ & 046667 & 4.7 & $8590(0.86)$ & 5.4 \\
\hline \multirow{4}{*}{84} & $0-10$ & 780176 & 78.0 & $1228(0.12)$ & 4.9 \\
\hline & $20-30$ & 116316 & 11.6 & $1775(0.18)$ & 3.4 \\
\hline & $40-60$ & 109206 & 10.9 & $3900(0.39)$ & 3.3 \\
\hline & $90-110$ & 020563 & 2.1 & $2577(0.27)$ & 3.1 \\
\hline \multirow{4}{*}{85} & $0-10$ & 720100 & 72.0 & - & - \\
\hline & $20-30$ & 357100 & 35.7 & $3187(0.32)$ & 4.6 \\
\hline & $40-60$ & 065810 & 6.6 & $4650(0.46)$ & 3.8 \\
\hline & $90-110$ & 027550 & 2.8 & $10066(1.01)$ & 3.5 \\
\hline \multirow{4}{*}{86} & $0-10$ & 776700 & 77.7 & - & - \\
\hline & $20-30$ & 186100 & 18.6 & $9570(0.96)$ & 4.7 \\
\hline & $40-60$ & 018190 & 1.8 & $24800(2.48)$ & 3.7 \\
\hline & $90-110$ & 015120 & 1.5 & $22500(2.25)$ & 3.3 \\
\hline
\end{tabular}

Fig. 2. Data of Quantitative Chemical Analysis of samples from the site 2.7.2598. 
Table 1. The oil pollution scale.

\begin{tabular}{|c|c|c|}
\hline $\begin{array}{c}\text { Oil } \\
\text { content, } \%\end{array}$ & Color & $\begin{array}{c}\text { An example of the } \\
\text { colour }\end{array}$ \\
\hline $0-1.0$ & green & \\
\hline $1.1-3.0$ & yellow & \\
\hline $3.1-6.0$ & orange & \\
\hline $6.1-10.0$ & light brown & \\
\hline $10.1-15.0$ & dark brown & \\
\hline $15.1-25.0$ & pink & \\
\hline $25.1-40.0$ & light red & \\
\hline$>40.0$ & dark red & \\
\hline
\end{tabular}

\subsection{Creation of 3D-models of plots with the display of each parcel in volume and color}

The 3D model in color reflects the $\mathrm{pH}$, chloride concentration, and volume of petroleum products in each section of the site. As a rule, the number of sections within the boundaries of one section does not exceed 4; the lower section is not deeper than $2.0 \mathrm{~m}$ (in our case, $1.1 \mathrm{~m}$ ). The top three sections of soil are available for reclamation: a) - 0-10 cm, b) - 10-30 cm, C) - 30-60 cm; d) $-60-110 \mathrm{~cm}$ (not available) [17].

\subsection{Distribution of sites and their parts to reclamation groups}

a) areas or parts thereof where biological remediation is required;

b) the plots or their parts, which do not require the use of biological remediation;

c) areas or parts of them where it is currently impossible to achieve the required results during biological remediation due to the lack of necessary or insufficient existing technologies;

d) areas or parts thereof where biological remediation is temporarily impractical due to the high probability of recontamination due to insufficient operational reliability of pipelines[18].

\subsection{Creating QR codes and parcel codes}

This encoding will speed up, objectify and unify the receipt and use of information. The parcel is the smallest part of the oil-contaminated area allocated at the intersection of the point zone and the layer. Each parcel has a number of characteristics and parameters. They can be encoded. For example, 2.55/84b/350/g. in this case, the cipher indicates: 1) the number of the site; the parcel in the area of point 84 of layer b; the volume is $350 \mathrm{~m} 3$; the excess of the content of petroleum products above the permissible level in the range from 31 to $40 \%$. There are many options for forms and types of encoding, and the main thing is to maintain uniformity. Parcel coding precedes QR coding (fig. 2).

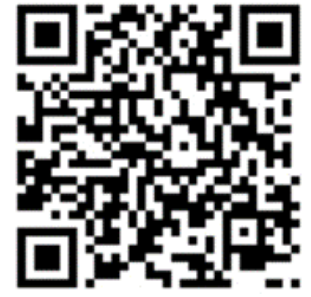

Fig. 2. QR code of a three-dimensional model of an oilcontaminated land plot.

\section{Results and Discussion}

For these purposes, we propose using 3D models of oilcontaminated sites, as well as tables with which you can calculate and determine the qualitative and quantitative data necessary for development.

The list of factors affecting the condition of each site and subject to accounting can be significant, but among the mandatory three should be distinguished: 1) the density of soil layers, 2) the content of oil products and 3) chlorides [19].They more often than others limit the body, affect the activity and migration of many substances. In order to adequately determine the condition of a contaminated site, it is necessary to understand the distribution of indicators of these three factors not only in area but also in depth. Therefore, it is necessary to build three-dimensional models (3D).

We will show the application of these models and tables on the example of one of the oil-contaminated sections of the Samotlor field under conditional registration number 2.7.2598. (fig. 3).

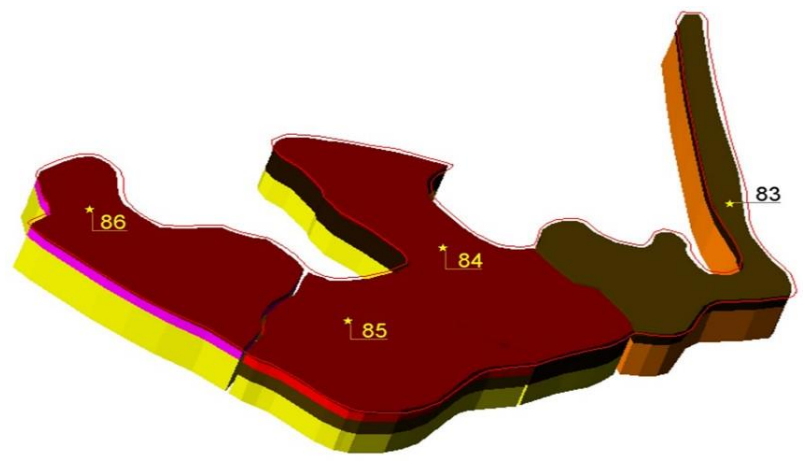

Fig. 3. The 3D-model of oil pollution of the site 2.7. 2598.

Today, the reclamation data used on the plots is not informative in terms of their actual condition. The main information is tied to the surface layer, rarely $15-20 \mathrm{~cm}$, rarely up to $30 \mathrm{~cm} \mathrm{[20].}$

To carry out effective reclamation of oilcontaminated sites, an adequate and accurate assessment of its condition and information about where and how pollution is distributed, what are the volumes of parts of sites that require different types of reclamation. It is also known that in many areas the restoration of biocenoses is more successful without reclamation work.

$3 \mathrm{D}$ models of oil-contaminated sites, as well as tables that can be used to calculate and determine the qualitative and quantitative data needed for remediation, help solve this problem. 
Table 2. The spatial parameters of the site № 2.7.2598.

\begin{tabular}{|c|c|c|c|c|c|c|}
\hline \multirow{2}{*}{ Location } & \multirow{2}{*}{$\begin{array}{c}\text { Area of the zone, } \\
\mathbf{m}^{2}\end{array}$} & \multicolumn{4}{|c|}{ The volume of layers, $\mathrm{m}^{3}$} & \multirow{2}{*}{ Total, $\mathbf{m}^{3}$} \\
\hline & & a $(0.1 \mathrm{~m})$ & b (0.2 m) & c $(0.3 \mathrm{~m})$ & $\mathrm{d}(0.5 \mathrm{~m})$ & \\
\hline 83 & 1344.172 & 134.417 & 268.834 & 403.252 & 672.086 & 1478.589 \\
\hline 84 & 1749.206 & 174.921 & 349.841 & 524.762 & 874.603 & 1924.127 \\
\hline 85 & 1498.700 & 149.870 & 299.740 & 449.610 & 749.350 & 1648.570 \\
\hline 86 & 1410.145 & 141.014 & 282.029 & 423.043 & 705.072 & 1551.158 \\
\hline Subtotal & 6002.223 & 600.222 & 1200.444 & 1800.667 & 3001.111 & 6602.444 \\
\hline
\end{tabular}

An analysis of open sources showed that there are three main degrees of oil pollution of soils:

1) weak - up to $10 \%$;

2) average - from 10 to $40 \%$;

3) strong - more than $40 \%$.

Low pollution dramatically reduces productivity and leads to the death of about $1 / 2$ of the vegetation. With average pollution, stands and shrubs die completely within 10 years. Heavy oil pollution completely destroys phytocenosis in the period up to 1 year [21].

Similar 3D models and tables for volumetric content were created for volumetric reflection of the concentration of chlorides and $\mathrm{pH}$ in the soils of oilcontaminated land plots [22].

\section{Conclusions}

The proposed method allows us to present the parameters of an oil-contaminated site in threedimensional and tabular form for a more accurate assessment of the state of oil-contaminated sites. Accurate assessment helps to carry out effective remediation, allowing you to pass the sites to environmental services. The 3D model in color reflects the $\mathrm{pH}$, chlorides, and petroleum products in each layer of soil. The use of barcodes will speed up the collection and processing of information, certification of all oilcontaminated sites, and the combination of a wide variety of databases from various industries.

The division of the parcel into parts: areas and parcel. Forming a hierarchical system of 3 levels for each site. 1 the smallest level - the parcel, as one of the four layers within the boundaries of the selection; 2 level-the selection of the site with a set of four parcels; 3 level the entire site in the aggregate of allotments and parcels [23].Systematization (classification and typologization) of the results of quantitative chemical analysis in tabular form. Scaling-differentiation of different concentrations of pollution by the characteristics of the impact on natural components, primarily living organisms [24]. Volumetric assessment of the parcel area to reflect the state of the parts and the site as a whole. Synthesisinterpretation of tabular data in the form of threedimensional models and diagrams. Codificationconverting numeric data into alphanumeric characters and symbols.

\section{References}

[1] E. Mukhametshina, I. Aitov, 3D-models as a method for reflecting volume and spatial parameters of oil-contamined sites, E3S Web of Conferences, 140 (2019).

[2] S. Davydova, V. Tagasov, Environmental pollution by oil and oil products, RUDN, Moscow (2006).

[3] S. Kulikov, N. Patrin, Remediation of oilcontaminated lands, Russia young: advanced technologies in industry, 3 (2013).

[4] R. Scopina, E. Panov, Reclamation of disturbed lands, Bibliographer, Moscow (1984).

[5] Ch. Vyalih, S. Shulga, Recultivation of lands, The Center. Chernozem, Voronezh (1980).

[6] T. Fedoseva, Recultivation of lands, Ear, Moscow (1977).

[7] G. Kolbasov, M. Rozanova, Use of industrial humates for reclamation of oil-contaminated peat soils, MGU, Moscow (2011).

[8] D. Stom, D. Potapov, Method of purification and reclamation of soils contaminated with oil and oil products, General issues of chemical technology, 19 (2005).

[9] S. Lushnikov, N. Mitrofanova, N. Tereschenko, Features of biological reclamation of oilcontaminated and technogenic-saline soils, Ecology and industry of Russia, 6 (2005).

[10] A. Muravev, B. Korryev, A. Lyzndzberg, Assessment of the ecological state of the soil, Christmas+, SPb (1999).

[11] A. Bannikov, Fundamentals of ecology and environmental protection, Ear, Moscow (1999).

[12] L. Astanin, K. Blagosklonov, Nature protection, Ear, Moscow (1984).

[13] L. Motorina, A. Savich, Ecological basis of land reclamation, Science, Moscow (1985).

[14] N. Cherkasova, Ecological basis of reclamation, Science, Moscow (1985).

[15] B. Chyzhov, V. Kozina, Forest and oil of KhantyMansi Autonomous Okrug, Yu. Mandriki, Tyumen (1998).

[16] Regional standard "Permissible residual content of oil and oil products in soils after reclamation and other restoration works on the territory of the Khanty-Mansiysk Autonomous Okrug-Ugra", approved by the resolution of the government of 
the Khanty-Mansiysk Autonomous Okrug - Ugra dated 10 December 2004, no. 466-p.

[17] K. Lopatin, State of environment and natural resources in Nizhnevartovsk district in 2003-2005, Yuogorski, Nizhnevartovsk (2006).

[18] I. Aitov, E. Kozelkova, E. Kuznecova, Typical types of negative impacts on license areas of oil companies in the area of cluster sites, Yuogorski, Nizhnevartovsk (2006).

[19] L. Dobrinski, V. Plotnikov, Ecology of KhantyMansi Autonomous Okrug, SoftDesign, Tyumen (1997).

[20] M. Kazanceva, S. Gashev, Monitoring studies at the site of an emergency oil spill in the taiga zone of Western Siberia, 1 (2000).

[21] M. Kazanceva, M. Cherkasova, E. Talipova, Formation of vegetation cover at the site of oil pollution remediation in the sub-taiga of Western Siberia, 6 (2011).

[22] J.P. Grime, Benefits of plant diversity to ecosystems: immediate, filter and founder effects, 6 (1998).

[23] L.R. Holdridge, Life zone ecology, Life zone ecology, 3 (1967).

[24] J.R. McLaren, R. Turkington, Ecosystem properties determined by plant functional group identity, Journal of Ecology, 98, 2 (2009). 